\title{
28. Tagung der European Accounting Association in Göteborg
}

Seminar Review

Bernhard Hirsch/Matthias Meyer

A uf der 28. jährlichen Tagung der European Accounting Association (EAA) waren deutsche Wissenschaftlerinnen und Wissenschaftler mit 39 Vorträgen stark vertreten. Gemeinsam mit 1.000 weiteren Wissenschaftlern aus Europa und Übersee hatten sie die Gelegenheit, im schwedischen Göteborg 594 Vorträge und Posterpräsentationen zu besuchen und sich so ein Bild über den aktuellen Stand der Forschung zum Rechnungswesen und Controlling zu machen.

Inhaltliche Schwerpunkte des Kongresses waren „Rechnungswesen und Vertrauen“, „Rechnungswesen und Ethik“, empirische Accounting-Forschung, $\mathrm{Zu}$ kunftsperspektiven der Accounting-Forschung und ein Dialog mit dem EAA Financial Reporting Standards Committee. $\mathrm{Zu}$ diesen Themen wurden eigene Symposien veranstaltet.

Die von den Wissenschaftlern aus aller Welt eingereichten Beiträge stammten zu einem großen Teil (97 von 594) aus dem Bereich Managerial Accounting/Controlling. Daneben waren Beiträge zum externen Rechnungswesen und zur Corporate Governance besonders stark vertreten. Mit 84 Beiträgen war Großbritannien vor den Vereinigten Staaten (58 Beiträge) die Nation mit den meisten Präsentationen. Alle Beiträge wurden einem Begutachtungsprozess unterzogen. Die Ablehnungsquote der eingereichten Beiträge lag bei 35 Prozent. Zahlreiche Beiträge basierten auf empirischen Studien.

Die große Zahl an Präsentationen von Forschern aus den USA und aus Australien (44 Paper) macht deutlich, dass sich die EAA Tagung inzwischen als internationale Plattform von Accounting-Forschern etabliert hat. Einen maßgeblichen

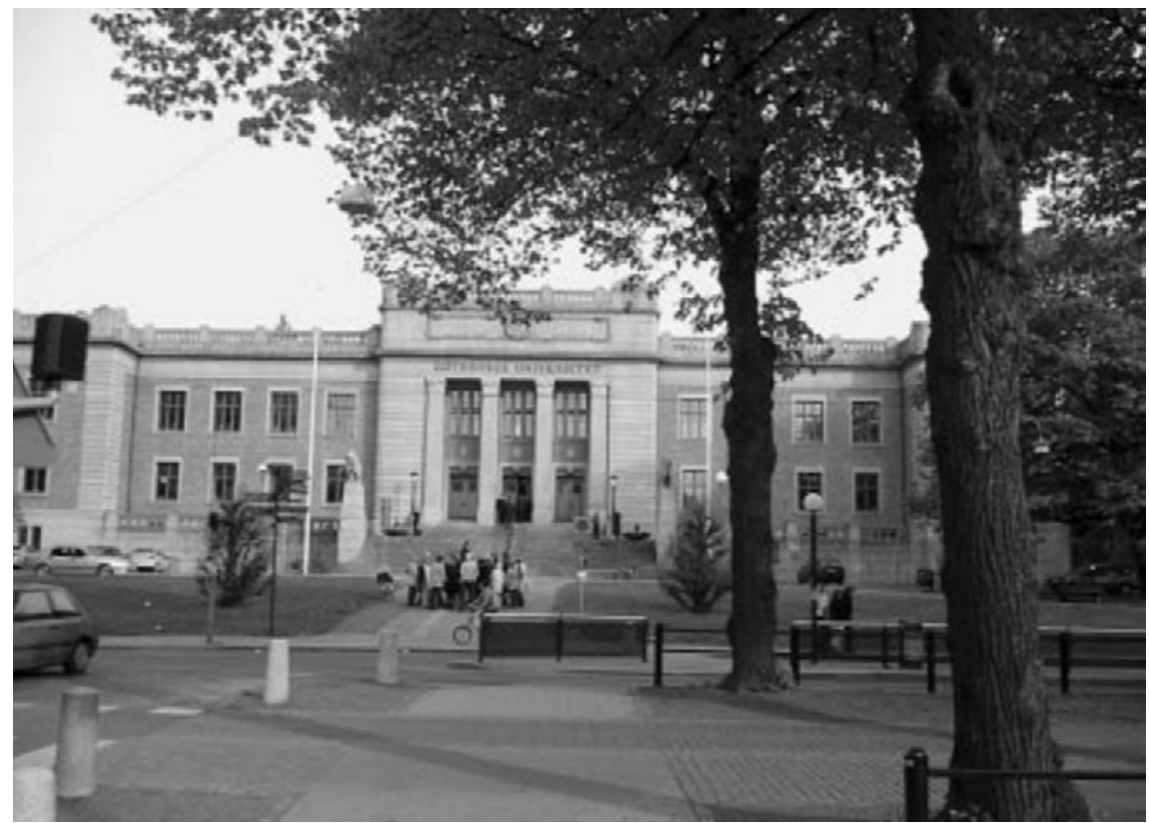

Anteil an dieser Entwicklung hat Anthony Hopwood, Professor an der Said Business School, Oxford University. Deswegen wurde dieser zu Beginn der Tagung von Bohumil Král, dem Präsidenten der EAA mit dem „Academic Leadership Prize“ ausgezeichnet. Hopwood selbst machte sich in einer kurzen Dankesrede für ein polyzentrisches Verständnis des Accounting stark und warnte davor, sich auf eine Forschungsmethode zu fokussieren.

Die Organisation der Tagung lag in den Händen der School of Economics and Commercial Law der Universität Göteburg. Dem Scientific Committee gehörten Wissenschaftler aus aller Welt, darunter auch aus dem deutschsprachigen Raum die Professoren Dieter Pfaff (Universität Zürich) und Reiner Quick (TU Darmstadt) an. Die Tagung fand in den Räumen der Universität statt. Zahlreiche Studenten waren mit der Betreuung und Gäste betraut.

Der nächste EAA Congress findet vom 22. bis 24. März 2006 in Dublin statt. Einsendeschluss für Paper ist bereits der 17. Oktober 2005. Weiter Informationen gibt es unter www.eaa2006.com im Internet.

Dr. Bernhard Hirsch und Dr. Matthias Meyer, MSc (LSE) 